\title{
Hora de repensar o modelo regulatório das comunicações? As recomendações da OCDE para o sistema público de radiodifusão no Brasil
}

\author{
Octavio Penna Pieranti' \\ https://orcid.org/0000-0002-2719-2431 \\ I - Universidade Estadual Paulista. \\ Bauru (SP). Brasil.
}

Resumo: Em outubro de 2020 a Organização para a Cooperação e Desenvolvimento Econômico (OCDE) publicou dois relatórios de avaliação das políticas públicas e da regulação do setor das comunicações no Brasil. Como o país tem ressaltado seu interesse em ingressar na OCDE e vem se adequando às manifestações da organização, as considerações feitas nos relatórios ganham mais relevância. O objetivo deste artigo é analisar as recomendações da OCDE para o modelo regulatório do setor no Brasil, centradas na instituição de um órgão regulador único e convergente, e para o sistema público de radiodifusão, dentre as quais está a revisão de alterações recentes na governança da EBC. Por terem sido recomendados pela OCDE, conclui-se que a mudança do modelo regulatório e os avanços no setor ganham força, porém sua efetiva implementação dependerá da superação de barreiras diversas.

Palavras-chave: OCDE; regulação; sistema público de radiodifusão.

Abstract: Is it time to reconsider the regulatory framework for communications? OECD recommendations for the public broadcasting system 
in Brazil - In October 2020, the Organization for Economic Cooperation and Development (OECD) published two reports evaluating public policies and regulation of the communications sector in Brazil. As the country has emphasized its interest in joining the OECD and has been adapting its procedures to the organization's manifestations, the reports' considerations are more relevant. The purpose of this paper is to analyze the OECD's recommendations for Brazilian communication's regulatory model, centered on the establishment of a single and convergent regulatory agency, and for public broadcasting, including the review of recent changes in EBC's governance. Because they have been recommended by the OECD, the change in the regulatory model and advances in the sector can progress, but their effective implementation will depend on overcoming various barriers.

Keywords: OECD; regulation; public broadcasting system.

\section{Introdução}

A Organização para a Cooperação e Desenvolvimento Econômico (OCDE) é formada por 37 países, articulados em torno da construção de políticas públicas para a consecução do objetivo mencionado em seu próprio nome. Atualmente a organização reconhece um país como candidato ao ingresso (Costa Rica) e cinco países parceiros centrais, entre eles o Brasil. Em 2017, o Brasil formalmente manifestou seu interesse em fazer parte da OCDE.

Essa adesão depende, em parte, de uma adequação ao que a OCDE define como "boas práticas" em diversas áreas. Assim, o sucesso do pleito do Brasil passará necessariamente por mudanças regulatórias e de políticas públicas nos mais diferentes setores, entre os quais o das comunicações. Em outubro de 2020, a OCDE publicou dois estudos analíticos sobre a regulação desse setor no Brasil: A Caminho da Era Digital no Brasil (OCDE, 2020a) e Avaliação da OCDE sobre Telecomunicações e Radiodifusão no Brasil 2020 (OCDE, 2020b).

Esses estudos são peer reviews desenvolvidos pela OCDE, devendo-se ressaltar que esse modelo de documento, a despeito de ser financiado pelo país interessado, é amparado pela mesma autonomia de iniciativas acadêmicas de peer review. Ou seja, os pesquisadores e demais profissionais da OCDE podem, a partir de sua análise do contexto nacional, realizar os elogios, críticas e sugestões que desejarem. Diferentemente do praticado no meio acadêmico, porém, a equipe da OCDE, antes da publicação do relatório, discute os resultados verificados com o financiador, no caso, o governo federal brasileiro. 
Este artigo tem por objetivo analisar as propostas da OCDE para o modelo regulatório das comunicações e para o sistema público de radiodifusão no Brasil a partir de uma revisão documental e bibliográfica. Em paralelo a essa análise, as diferentes questões apontadas serão contextualizadas com base na literatura produzida sobre o tema.

O documento Avaliação da OCDE sobre Telecomunicações e Radiodifusão no Brasil 2020 (OCDE, 2020b) é central a esta análise. Vale lembrar que o texto, com um total de 266 páginas, vai muito além da discussão do modelo regulatório e do sistema público de radiodifusão. São tratados diversos temas abordados no campo das comunicações atualmente e que não serão objeto de análise deste artigo. Dentre eles, podem ser citados, por exemplo, a reforma na legislação de telecomunicações, questões tributárias, sistema privado de radiodifusão e a promoção da concorrência.

Na próxima seção deste artigo serão apresentados, de forma breve, os antecedentes do pleito brasileiro de ingresso na OCDE. A seguir, serão abordadas as considerações da organização sobre o modelo regulatório implementado no Brasil, baseado na coexistência de órgãos da administração direta e de duas agências reguladoras. Precedendo a seção de considerações finais, a quarta seção deste artigo tratará das mudanças propostas para o sistema público de radiodifusão.

\section{Breve histórico do pleito brasileiro de entrada na OCDE}

A despeito de seu pedido formal de ingresso na OCDE datar apenas de 2017, o Brasil começou a cooperar com a organização há mais de vinte anos. De acordo com levantamento do governo federal (BRASIL, 2019), até março de 2019, o país já havia participado de cerca de trinta comitês e grupos de trabalho da OCDE e aderido a 73 instrumentos legais da entidade.

Em 2007, essa cooperação começou a ser realizada de forma mais estruturada, visto que, naquele ano, o Conselho da OCDE decidiu ampliar suas parcerias com Brasil, China, Índia, Indonésia e África do Sul. Como resultado desse trabalho, em 2012, esses cinco países foram elevados à condição de parceiros-chave (key partners na terminologia oficial). Três anos depois, Brasil e OCDE assinaram um acordo de cooperação e, em 2017, como já mencionado, o Brasil solicitou seu ingresso formal na organização, tendo sido o primeiro parceiro-chave a formalmente fazer essa requisição. A seguir, o Brasil solicitou adesão a outros 63 instrumentos legais da OCDE, por considerar que já comungava das mesmas regras nacionalmente. 
Em março de 2019, o governo federal considerava-se apto a aderir a outros 72 instrumentos legais, perfazendo um total de $83,87 \%$ de instrumentos da organização que já estariam condizentes com a legislação e as políticas públicas brasileiras. No entanto, os demais documentos ainda não eram condizentes com as práticas nacionais ou ainda precisavam ser analisados (BRASIL, 2019).

No fim de 2018, o governo federal contratou o peer review da OCDE para o campo das comunicações, com o objetivo de obter uma revisão ampla, de entidade externa, sobre as políticas públicas e a legislação do setor e identificar seus pontos fortes e fracos. Quando um país decide estabelecer uma parceria como esta, é natural que dele se espere uma receptividade para adotar ao menos parte das recomendações apresentadas. Neste caso concreto, as expectativas vão além, já que o Brasil vem se esforçando para adequar-se às recomendações da OCDE, objetivando ver aceito seu pedido de ingresso na organização. Assim, ainda que não seja obrigatório, é de se supor que o país, também no campo das comunicações, venha a acatar parte das propostas.

Publicado o documento Avaliação da OCDE sobre Telecomunicações e Radiodifusão no Brasil 2020 (OCDE, 2020b), em outubro de 2020, resta agora projetar seus possíveis desdobramentos. E é deles que se tratam as seções seguintes deste artigo.

\section{A revisão do modelo regulatório}

Ultrapassadas as seções preliminares do documento - como prefácio, sumário e lista de siglas - , chega-se ao resumo executivo, que inclui cinco recomendações. A primeira delas é clara:

A criação de um regulador convergente e independente ajudaria a simplificar o regime regulatório e abordar a nova realidade convergente. Uma única entidade deveria outorgar espectro para os serviços de radiodifusão e de telecomunicação (OCDE, 2020b, p. 16).

De acordo com a OCDE (2020b), com o avançar da tecnologia nas últimas décadas, observou-se um cenário de convergência de redes e plataformas, eliminando ou minimizando os limites anteriormente existentes entre serviços do campo das comunicações. Diversos grupos econômicos passaram a expandir suas atividades, indo além das que costumavam desenvolver nas décadas anteriores. Um exemplo disso é a possibilidade de oferta de serviços de voz, dados e vídeo por um mesmo agente econômico. 
Essa ramificação leva, ainda segundo a organização, a uma necessidade de revisão do marco regulatório com o objetivo de encarar todo o setor segundo uma mesma lógica. Novamente a título de exemplo, convém lembrar que a radiodifusão é tratada, no Brasil, em grande parte, por lei específica (lei $n^{\circ} 4.117$ de 1962); as telecomunicações, por outro diploma (lei n 9.472 de 1997); o serviço de radiodifusão comunitária, por outro (lei nº 9.612 de 1998); e a TV por Assinatura, por um quarto (lei $n^{\circ} 12.485$ de 2011). Quase cinquenta anos separam a primeira lei citada da última. A elas se soma um intrincado cipoal regulatório, integrado por leis, decretos, resoluções, portarias e outras normas que, editadas em momentos políticos e econômicos muito distintos, nem sempre dialogam entre si.

Com base nesse cenário e com a expectativa de atingir uma simplificação regulatória, a OCDE recomenda a instituição de um órgão regulador unificado, não responsável pela formulação de políticas públicas, porém responsável pelas outorgas de todos os serviços de comunicações, quando aplicáveis (aí compreendida, inclusive, a radiodifusão). Essa proposta suscita diversas considerações relacionadas à (a) criação de um órgão regulador único; (b) à separação entre as atividades de formulação de políticas públicas e regulação; e (c) à atribuição da competência de outorgar ao órgão regulador.

Inicialmente, cabe lembrar que, no Brasil, a regulação do setor das comunicações se divide entre diversos órgãos. Pelo menos três poderiam ser considerados reguladores típicos, eis que responsáveis por desempenhar atividades inerentes à regulação: de forma resumida, Ministério das Comunicações (no caso da radiodifusão), Anatel (em telecomunicações, gestão do espectro e fiscalização da radiodifusão) e Ancine (no que tange, em parte, à TV por Assinatura). Outros órgãos e entidades detêm competências que também dialogam com a atividade regulatória, como o CGI e o Cade.

A proposta da OCDE, ao se referir a órgão regulador único, não parece tratar desses últimos, e sim dos três primeiros. Há indícios de que originalmente, quando implementado na década de 1990, o modelo tendia a caminhar nesse sentido. À época, a revisão do modelo regulatório das telecomunicações culminou na promulgação da lei n 9.472, conhecida como Lei Geral de Telecomunicações, na criação da Anatel (ambas em 1997) e na privatização do Sistema Telebrás (1998), objetivo maior. Para isso, foi necessário evitar atritos com o empresariado de radiodifusão, presente e com forte influência sobre o Congresso Nacional (RAMOS, 1997) e adversário de uma mudança de impacto no modelo regulatório aplicado ao setor: 
A dissidência entre telecomunicações e radiodifusão não encontra amparo no campo da ciência e nem no da técnica. É uma elaboração política, de sentido meramente conjuntural, perfeitamente datada e identificada com os interesses que a motivaram: resultou de um estratagema, urdido na reforma constitucional de 1995 pelo empresariado de radiodifusão 'para escapar à jurisdição do novo órgão regulador' concebido para atuar sobre as telecomunicações [...] (HERZ, 1997, p. 2).

O ministro das Comunicações à época, Sérgio Motta, parecia, contudo, ter planos distintos (PRATA; BEIRÃO; TOMIOKA, 1999), que levariam a uma agência de comunicações responsável não só pela regulação das telecomunicações, mas também da radiodifusão e dos serviços postais. Isso se refletiu em declarações públicas a respeito do tema e na incorporação, aos quadros da nascente Anatel, de profissionais com perfil e experiência de atuação nos dois outros segmentos. A morte do ministro, a instabilidade do ministério e a conjuntura política impediram o prosseguimento do plano original. Em 2001, a Ancine foi criada com competências principalmente relacionadas ao fomento do setor audiovisual, apenas recebendo competências regulatórias mais efetivas com o advento da lei $n^{\circ} 12.485$, promulgada dez anos depois e responsável por disciplinar o segmento de TV por Assinatura.

Assim, pode-se dizer que a conformação do modelo regulatório das comunicações iniciou-se no governo de Fernando Henrique Cardoso, como um preparativo para a privatização das prestadoras de telecomunicações então existentes, até a consolidação, em 2011, no governo de Dilma Roussef. Nesse ínterim, chegaram a ser pontualmente imaginadas mudanças nessa arquitetura institucional, por exemplo, no episódio que envolveu a proposta de uma agência reguladora do audiovisual, a Ancinav, em 2004, durante o governo Lula. Nem essa, nem outras ideias foram concretizadas, barradas, em grande parte, por força dos obstáculos criados pelo setor empresarial, refratário à discussão regulatória e com fortes relações com parte significativa dos parlamentares (JAMBEIRO, 2002; MATTOS, 2005).

Destaca-se, ainda, um outro momento em que esse tema foi amplamente debatido. No fim de 2009, ocorreu a I Conferência Nacional de Comunicação - Confecom, evento ao qual se opôs parte significativa dos meios de comunicação privados e no qual foram formuladas diversas propostas sobre a regulação das comunicações no país (CASTRO, 2020). Os anos seguintes seriam marcados por um debate sobre o novo marco regulatório para as 
comunicações brasileiras. Em 2010, o então ministro-chefe da Secretaria de Comunicação Social da Presidência da República, Franklin Martins, coordenou um grupo de trabalho composto por representantes de diversos órgãos e entidades federais para tratar das bases de uma nova lei e relembrou, em entrevista posterior, o debate sobre o órgão regulador único:

Houve uma discussão sobre o que era mais razoável - uma ou duas agências. Nesse caso, uma agência para cuidar da parte de infraestrutura, que é o que a Anatel faz hoje, e uma outra para cuidar da regulação de conteúdo, como cota regional, produção independente, respeito ao menor. Acabou-se optando, no âmbito do governo, por duas agências, a Anatel e a Agência Nacional de Comunicações (ANC). Mas a ANC não era um desdobramento da Ancine, porque a Ancine hoje, a meu ver erradamente, tem duas funções - ela regula e fomenta. Eu acho que quem fomenta não deve regular. Acho que precisava separar as duas funções, talvez criando uma instituição como uma Finep na Cultura. Seria uma agência de fomento, e a outra seria uma de regulação. Acabou prevalecendo a ideia das duas agências, da Anatel e da ANC, mas vou ser franco: não tenho certeza de que essa é a melhor solução. Por que essa solução prevaleceu? Porque se fosse uma agência só, o conteúdo seria tratado pela Anatel. E, como essa agência tem uma vasta tradição de lidar com infraestrutura, a regulação de conteúdo tenderia a desaparecer ali dentro, seria um rabicho da Anatel. O modelo ideal seria o que existe em vários países: uma agência, mas com dois conselhos para tratar separadamente os dois grupos de assuntos (PIERANTI, 2019, p. 210-211).

Mais uma vez, a discussão não resultou sequer no envio de um projeto de lei sobre o tema ao Congresso Nacional e, por óbvio, nem tampouco na promulgação de lei que revisse a divisão de competências da administração pública. Em momentos posteriores, esse debate ocorreu principalmente na esfera acadêmica e, em outubro de 2020, foi retomado com a publicação do relatório da OCDE tratado neste artigo.

Como mencionado, a proposta da organização frisa a necessidade de se separar formulação de políticas públicas de regulação. Essa distinção consta de documentos apresentados à época da Reforma do Aparelho de Estado, na década de 1990, e de reflexões, por exemplo, de Bresser-Pereira, então ministro e principal idealizador da reforma (BRESSER-PEREIRA, 2000; BRESSERPEREIRA, 2005). Não por acaso, a lei $n^{\circ}$ 9.472, ao definir as competências da 
Anatel, atribuiu a ela, além da regulação, a atividade de implementação de políticas públicas, já que a formulação de políticas para o setor continuaria sendo atribuição do Ministério das Comunicações.

Essa separação de competências pode ser observada, de forma clara, em alguns processos da administração. Como exemplo, pode-se citar que Presidência da República e Ministério das Comunicações trabalharam em decretos de formulação dos Planos Gerais de Metas de Universalização (PGMU), ao passo que coube à Anatel trabalhar na implementação desses planos, estabelecendo e acompanhando o cumprimento de regras específicas voltadas ao atingimento das metas estabelecidas.

Por outro lado, modelos teóricos próprios da ciência política e da administração pública, ao invés de encararem políticas públicas como um conjunto de etapas bem separadas, costumam defendê-las como um fluxo contínuo ou ciclo em que atividades se sucedem e se retroalimentam (CAPELLA, 2018; LOTTA, 2019). Assim, formulação e implementação acabam por se complementar, nem sempre sendo possível estabelecer limites totalmente precisos entre elas.

A terceira parte da recomendação da OCDE diz respeito à atribuição da atividade de outorgar ao regulador único. Com efeito, desde que foi criada, a Anatel passou a ser a responsável por outorgar serviços de telecomunicações, o que significou não apenas desempenhar essa atividade para serviços utilizados pelo público em geral, como o de telefonia móvel, mas também para serviços voltados a públicos mais reduzidos, como os de radioamadorismo e de rádio-táxi. Agência reguladora com competência de outorga, assim, é uma constante do setor das comunicações há mais de duas décadas, porém não é tão comum em outros mercados regulados e, inclusive, essa competência já gerou debates acirrados no âmbito do processo que viria a resultar na lei $n^{\circ} 13.848$ de 2019, a Lei das Agências Reguladoras (TELETIME, 2007).

A proposta da $O C D E$, se implementada, significaria transferir ao órgão regulador também a competência para outorgar os serviços de radiodifusão, atualmente competência do Ministério das Comunicações. Um primeiro elemento a se considerar diz respeito aos prazos de outorgas: a despeito de tentativas de desburocratização e de revisões do fluxo desses processos, outorgas de radiodifusão são historicamente reconhecidas como demoradas e sujeitas em demasia à discricionariedade política (MOTTER, 1994; COSTA; BRENER, 1997; LOPES, 2009). Enquanto isso, a Anatel tem implementado 
medidas consistentes de aceleração do processo de outorgas, que culminaram, inclusive, na desnecessidade das mesmas para serviços específicos. Adicionalmente, no Brasil, as agências reguladoras tendem a ser submetidas a processos mais estáveis e objetivos que os ministérios. A Anatel, por exemplo, por força de lei ou de outros instrumentos normativos, deve realizar consultas públicas para alterar regulamentos e mantém ou regulamenta ao menos três instâncias de controle social (conselho consultivo, Comitê de Defesa dos Usuários de Serviços de Telecomunicações e conseIhos de usuários). Já ao Ministério das Comunicações não se aplicam regras que impliquem em obrigatório diálogo com a sociedade em uma dinâmica estruturada de controle social.

Vale lembrar, aliás, que a perspectiva de atrelar outros agentes ao processo regulatório vem sendo defendida pela OCDE. Cite-se, como exemplo, texto disponibilizado no portal da própria organização:

[...] fortalecer terceiros (comerciais e não comerciais) para atuarem como reguladores 'substitutos', alcançando, assim, não apenas melhores resultados a um custo menor, mas também oferecendo recursos regulatórios para situações em que a intervenção do governo não é possível (GUNNINGHAM; SINCLAIR, 1998).

Ressalte-se que essa abordagem salutar de incorporar terceiros à regulação significa não apenas conferir à sociedade civil novo papel, como também criar um ambiente institucional permanente de discussão com agentes privados que, como já mencionado, historicamente impuseram obstáculos ao avanço desse debate. Assim, a mudança no modelo regulatório ocorrerá apenas se dirimidas essas barreiras, no contexto do debate legislativo, e imagina-se que implicará, se aprovada, em um conjunto de novas práticas mais abertas à participação dos diferentes grupos.

A título de exemplo, vale avaliar rapidamente qual seria a implicação da proposta da OCDE em um caso concreto. A partir de 2011, o Ministério das Comunicações criou e divulgou Planos Nacionais de Outorgas (PNOs), ou seja, calendários que reuniam listas de municípios para os quais seriam publicados editais com vistas a novas outorgas de serviços de radiodifusão. Esses planos eram disponibilizados no portal do ministério e deles também constavam os critérios para a definição dos municípios incluídos (PIERANTI, 2017). Em 2016, com a mudança no governo federal, a nova gestão 
do ministério simplesmente interrompeu os PNOs divulgados ou reduziu a publicação de editais.

A medida, por óbvio, prejudicou interessados na prestação dos serviços de radiodifusão. Isso teria sido possível, se fosse o órgão regulador o responsável por outorgar? Considerando a legislação que rege a Anatel, qualquer mudança desse nível provavelmente teria que ser submetida à consulta pública e se sujeitaria a manifestações por parte de instâncias de controle social existentes.

Os PNOs mencionados tratavam de radiodifusão educativa e comunitária. Não por acaso, a OCDE foi crítica ao analisar o sistema público de radiodifusão no Brasil.

\section{Mudanças no sistema público de radiodifusão}

Assim como ao analisar mudanças no modelo regulatório, a OCDE foi incisiva em sua recomendação sobre radiodifusão pública: “Fortalecer o sistema público de radiodifusão ${ }^{1}$ nacional ao garantir financiamento suficiente e a independência editorial das emissoras públicas, incluindo a EBC" (OCDE, 2020b, p. 50). De acordo com a organização, falta uma política pública coordenada que possibilite ampliar a cobertura do sistema público de radiodifusão, o que poderia ser alcançado por um compartilhamento de infraestrutura entre emissoras com perfil semelhante ao das mantidas pela Empresa Brasil de Comunicação (EBC).

Também criticou a ausência de fontes estáveis de financiamento e as mudanças na governança da EBC, que implicaram em perda de independência por parte das emissoras por ela geridas. Nesse ponto, a OCDE refere-se à lei $n^{\circ} 13.417$ de 2017, decorrente de uma das primeiras medidas provisórias do governo Temer. Dentre outras providências, a nova lei extinguiu o conselho curador da EBC e o instituto do mandato fixo para seu diretor-presidente.

Assim, a OCDE reforça pontos pacíficos e aparentemente consensuais para pesquisadores de emissoras públicas no mundo, como, por exemplo, Kops (2001), Banerjee e Seneviratne (2005) e Abashina (2016), e que podem ser resumidos na figura a seguir: 


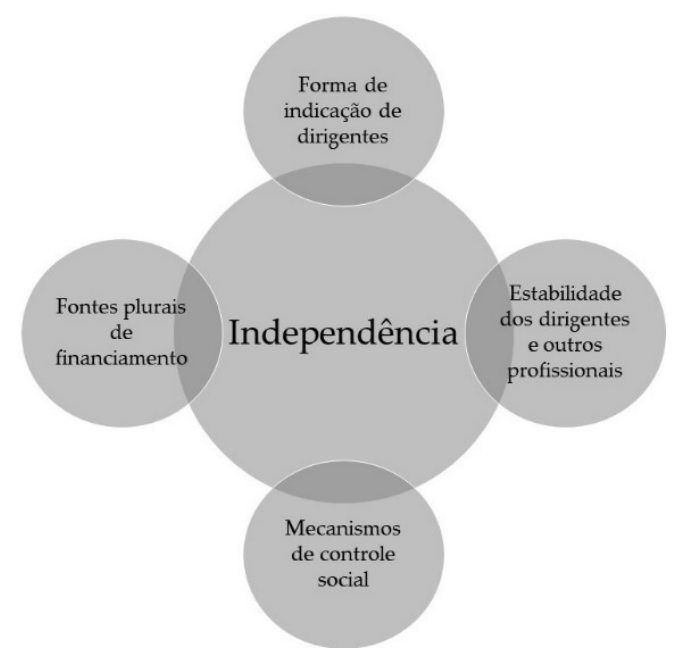

Figura 1. Fonte: (PIERANTI, 2018)

A fusão entre as programações da TV Brasil (considerada integrante do sistema público) e da NBR (canal institucional de transmissão de notícias do poder executivo), em 2019, foi capítulo importante nos ataques a esse modelo. Porém, antes dessa medida, a lei nº 13.417 de 2017 já havia incidido diretamente sobre dois dos quatro pilares inerentes à garantia da independência por emissoras públicas.

Esse conjunto de medidas foi alvo de críticas nos últimos anos. Logo depois da fusão das programações, até desenhos animados passaram a ser interrompidos pela transmissão de atos do governo federal, incluindo homenagens ao Dia do Exército (MADEIRO, 2019). A seguir, aumentaram denúncias públicas de censura interna, eventualmente organizadas em dossiês formulados por representantes dos empregados da EBC e de sindicatos (ABI, 2020). Também foi criada pela Frente em Defesa da EBC uma "ouvidoria cidadã", que se propôs, no fim de 2020, a acompanhar, de forma crítica, a programação veiculada pela TV Brasil (FENAJ, 2020). Em janeiro de 2020, o secretário do governo federal declarou que a EBC seria privatizada dali a dois anos (HOMERO, 2020). Esse representante do poder executivo deixou o cargo meses depois. Ainda assim, em março de 2021, o governo federal incluiu a EBC no Programa Nacional de Desestatização (PND), uma medida inicial para a realização de estudos sobre a possível privatização da empresa (LIS, 2021). 
Um terceiro pilar, as fontes diversificadas e estáveis de financiamento, já era frágil, tendo em vista um orçamento variável e problemas jurídicos envolvendo a Contribuição ao Fomento da Radiodifusão Pública (CFRP), o que impedia a efetividade desse mecanismo (PIERANTI, 2018). Ainda não havia sido implementado, no Brasil, o outro pilar, a saber, uma forma de indicação de dirigentes que envolvesse diferentes atores políticos (por exemplo, o Congresso Nacional) como forma de dissipar vínculos excessivos entre o presidente da república e o diretor-presidente por ele indicado para a EBC.

Para além da situação dessa empresa e do sistema público de radiodifusão, verifica-se, na abordagem da OCDE, uma preocupação com o "ecossistema" que compõe o que outrora chegou a ser reconhecido, no Brasil, como o “campo público" articulado durante o I Fórum Nacional de TVs Públicas, terminado em 2007. Em outras palavras, a OCDE preocupa-se, em seu relatório, com rádios comunitárias, canais comunitários de TV, canais estatais vinculados a poderes e outros que se colocam como alternativas à mídia comercial.

Sem almejar uma análise exaustiva - até mesmo em função da limitação de espaço deste artigo - convém abordar brevemente alguns pontos. A OCDE ressalta, no âmbito do que pode ser considerado parte do sistema estatal de radiodifusão, a expansão da rede legislativa e o início da transmissão, em 2015, de canais mantidos pelo poder executivo como faixas de multiprogramação da TV Brasil.

No que tange ao sistema público, considera, ainda, que a digitalização da TV no Brasil não fornece oportunidades concretas a canais comunitários. Ao analisar a lei $n^{\circ} 9.612$ de 1998 e a normatização infralegal, a OCDE constata que o processo de outorga de rádios comunitárias é excessivamente demorado e que esse segmento enfrenta "muitos obstáculos sob a legislação brasileira":

Essas leis proíbem os radiodifusores comunitários de formarem qualquer rede, o que limita consideravelmente a forma de eles compartilharem infraestruturas, por sua vez limitando como alavancar os recursos uns dos outros para reduzirem os custos para cada uma de suas respectivas comunidades. Eles não podem transmitir quaisquer anúncios publicitários e não Ihes foi disponibilizado qualquer financiamento público (OCDE, 2020b, p. 223).

De fato, a organização chama atenção para pontos que, há muito, têm constado da pauta de discussão de rádios comunitárias (PERUZZO, 2010; BROCK; MALERBA, 2013). O financiamento dessas emissoras é capítulo não 
equacionado pela legislação brasileira, visto não ir além da tímida previsão de que rádios comunitárias podem realizar apoio cultural (PIERANTI, 2017). Ora, o financiamento do setor de radiodifusão, no Brasil, baseia-se principalmente em publicidade comercial, essencial às emissoras privadas, ou em orçamento público, central a estações vinculadas a governos. Como não prevê nenhuma dessas fontes ou uma eventual substituta para a radiodifusão comunitária, a lei exime-se de garantir um modelo que assegure sustentabilidade a essas emissoras.

Por fim, cabe destacar que uma adequação às recomendações feitas pela OCDE sobre o sistema público de radiodifusão passa necessariamente por mudanças no modelo regulatório. O compartilhamento da infraestrutura entre diversas emissoras, a demora nas outorgas, a ausência de soluções integradas de financiamento, dentre outros problemas apontados no relatório, depende, em parte, de mudanças na legislação e de medidas regulatórias tomadas de forma coordenada, capazes de consolidar um olhar convergente sobre as comunicações brasileiras em suas múltiplas perspectivas.

\section{Considerações finais}

Procurou-se apresentar, nas páginas anteriores, as recomendações da OCDE sobre o modelo regulatório brasileiro para as comunicações e para o sistema público de radiodifusão. Também se buscou relatar o contexto em que essas recomendações foram formuladas.

Em síntese, a OCDE recomendou a criação de um órgão regulador único e convergente, responsável também por outorgar, e diversas mudanças na legislação. Além disso, recomendou a reversão das mudanças na governança da EBC, o que significa retomar o mandato fixo do seu diretor-presidente e o conselho curador; o estabelecimento de mecanismos estáveis de financiamento para a empresa; o compartilhamento de infraestrutura entre as estações; um modelo de sustentabilidade aceitável para rádios comunitárias; e a simplificação de processos de outorga, dentre outras medidas.

Como demonstrado nas páginas anteriores, várias dessas recomendações vão ao encontro de sugestões de outros estudos e reflexões formulados ao longo das últimas décadas. Um modelo centrado em uma agência reguladora única tende a contribuir para uma maior eficiência de suas atividades e a estabelecer uma lógica de atuação coesa; além disso, a depender das finalidades a que se propõe e do grau de incorporação de outros atores ao 
processo regulatório, pode gerar diversos avanços, como a implementação de políticas públicas e ações coordenadas capazes de garantir direitos e fomentar o pluralismo. Cabe, agora, tratar brevemente de uma questão que se impõe: qual é a chance real de efetivação dessas recomendações no presente?

Sobre isso, vale lembrar que a OCDE apresentou recomendações, termo mais incisivo que sugestões, porém mais tímido que ordens. Mesmo que a OCDE não tenha imposto suas considerações (o que obviamente fugiria ao seu mandato), em um contexto em que o Brasil almeja ingressar na organização, vem sendo verificada boa vontade do governo federal em (tentar) adequar-se a recomendações formuladas pela organização, o que também foi abordado em seções anteriores.

Essa boa vontade, perceptível, ao longo dos últimos anos, nos documentos citados, traz expectativas positivas quanto a medidas que foram, nas últimas décadas, no setor das comunicações, descartadas pelos mais diferentes motivos. Desinteresse de vários governos, trocas de gestões nos órgãos responsáveis por essa pauta, falta de consenso no Congresso Nacional, atuação de alguns grupos de interesse e ineficiência de outros, ausência de conhecimento técnico, fragilidades das próprias organizações, dentre tantos outros motivos, ajudam a explicar por que problemas evidentes, como a ausência de um modelo de financiamento para a radiodifusão comunitária, não foram tratados a contento pela legislação nacional. Várias dessas justificativas aplicaram-se no passado - e podem vir a se repetir no presente e no futuro, mesmo face às recomendações da OCDE.

Assim, pode-se dizer que a chancela dessa organização, no momento em que o Brasil planeja nela ingressar, sugere uma maior chance de aceitação de, pelo menos, parte dessas recomendações. Isso não significa dizer, porém, que é certa a adoção de qualquer uma delas.

Octavio Penna Pieranti é professor do Programa de Pósgraduação em Mídia e Tecnologia na Unesp e realiza pós-doc na UFRJ; é doutor em administração e mestre em administração pública pela FGV, com pós-doutorado em Comunicação na Unb. 


\section{Referências}

ABASHINA, E. Public service media in Transcaucasian countries. Strasbourg: European Audiovisual Observatory, 2016.

ABI. Dossiê revela censura em matérias da EBC. ABI, 18 set. 2020. Disponível em: <http:// www.abi.org.br/dossie-mostra-censura-em-reportagens-da-ebc/>. Acesso em: 16 fev. 2020.

BANERJEE, I.; SENEVIRATNE, K. Public service broadcasting: a best practices sourcebook. Paris: Unesco, 2005.

BRASIL. Brazil's Candidacy for OECD Membership: Where We Are Now. 2019. Disponível em: <https://www.gov.br/casacivil/pt-br/centrais-de-conteudo/downloads/ocde/material-institucional/brazils-candidacy-for-oecd-membership-where-we-are-now-abr2019.pdf>. Acesso em: 30 out. 2019.

BRESSER-PEREIRA, L. C. Revista de Administração Pública - RAP, 34(4): p. 7-26, jul.-ago. 2000. Disponível em: <http://bibliotecadigital.fgv.br/ojs/index.php/rap/article/ download/6289/4880>. Acesso em: 20 jun. 2020.

. Da administração pública burocrática à gerencial. In: BRESSER PEREIRA, L. C.; SPINK, P. (orgs.). Reforma do Estado e Administração Pública Gerencial. São Paulo: FGV, 2005, 6 ed., p. 237-270.

BROCK, N.; MALERBA, J. P. Um ar mais livre? Uma breve abordagem comparativa da situação legal das rádios comunitárias na Europa e América do Sul. In: IX Conferência Brasileira de Mídia Cidadã. 2013. Disponível em: <http://midia.pgr.mpf.gov.br/pfdc/hotsites/radioscomunitarias/docs/pesquisa-comparativa-paises-europeus.pdf>. Acesso em: 10 jul. 2020.

CAPELLA, A. Formulação de Políticas Públicas. Brasília-DF: Enap, 2018, p. 13-107. Disponível em: <http://repositorio.enap.gov.br/bitstream/1/3332/1/Livro_ Formula\%C3\%A7\%C3\%A30\%20de\%20pol\%C3\%ADticas\%20p\%C3\%BAblicas.pdf>. Acesso em: 20 jun. 2020.

CASTRO, J. A Conferência que virou (quase só) história. Reciis - Revista Eletrônica Comunicação, Infomação, Inovação e Saúde, 14 (1): 12-7, jan.-mar. 2020. Disponível em: <https:// www.arca.fiocruz.br/bitstream/icict/40871/2/4.pdf>. Acesso em: 16 dez. 2020.

COSTA, S.; BRENER, J. Coronelismo eletrônico: o governo Fernando Henrique e o novo capítulo de uma velha história. Comunicação \& Política, Rio de Janeiro, vol. 4, n. 2, p. 29-53, 1997.

FENAJ. Frente em Defesa da EBC lança Ouvidoria Cidadã. FENAJ, 16 dez. 2020. Disponível em: <https://fenaj.org.br/frente-em-defesa-da-ebc-lanca-ouvidoria-cidada/>. Acesso em: 16 dez. 2020.

GUNNINGHAM, N.; SINCLAIR, D. Smart Regulation: Designing Environmental Policy. Oxford, UK: Oxford University Press, 1998. Disponível em: <https://www.oecd.org/env/ outreach/33947759.pdf>. Acesso em: 30 out 2020. 
HERZ, D. A renúncia a uma política de telecomunicações, em nome da telefonia e da radiodifusão. In: Congresso Brasileiro de Ciências da Comunicação, XX, 1997, Santos. Anais. Santos, SP: INTERCOM, 1997.

JAMBEIRO, O. A TV no Brasil do Século XX. Salvador: EdUFBA, 2002.

KOPS, M. What is Public Service Broadcasting and How Should It Be Financed? Cologne: University of Cologne, Sept. 2001. Working Paper.

LIS, L. Governo inclui EBC em plano de desestatização, primeiro passo para privatizar a empresa. G1, 16 mar. 2021. Disponível em: <https://g1.globo.com/economia/ noticia/2021/03/16/governo-inclui-ebc-em-plano-de-desestatizacao-primeiro-passo-para-privatizar-a-empresa.ghtml>. Acesso em: 24 abr. 2021.

LOPES, C. Regulação das outorgas de radiodifusão no Brasil - uma breve análise. Câmara dos Deputados, dez. 2009. Disponível em: <https://bd.camara.leg.br/bd/bitstream/handle/ bdcamara/5404/regulacao_outorgas_lopes.pdf?sequence=3\&isAllowed=y>. Acesso em: 30 out. 2020.

LOTTA, G. A política pública como ela é: contribuições dos estudos sobre implementação para a análise de políticas públicas. In: LOTTA, G. (Org.) Teoria e análises sobre implementação de políticas públicas no Brasil. Brasília: Enap, 2019, p. 11-38. Disponível em: <https:// repositorio.enap.gov.br/bitstream/1/4162/1/Livro_Teorias\%20e\%20An\%c3\%a1 lises\%20 sobre\%20Implementa\%c3\%a7\%c3\%a30\%20de\%20Pol\%c3\%adticas\%20P\%c3\%bablicas\%20 no\%20Brasil.pdf>. Acesso em: 27 jun. 2020.

HOMERO, V. Governo quer privatizar Correios e EBC até janeiro de 2022. Poder 360, 29 jan. 2020. Disponível em: <https://www.poder360.com.br/economia/governo-quer-privatizar-correios-e-ebc-ate-janeiro--de-2022/>. Acesso em: 16 dez. 2020.

MADEIRO, C. Nova TV Brasil é marcada por denúncias de censura e "overdose de governo". UOL, 25 abr. 2019. Disponível em: <https://noticias.uol.com.br/politica/ ultimas-noticias/2019/04/25/nova-tv-brasil-e-marcada-por-denuncias-de-censura-e-overdose-de-governo.htm>. Acesso em: 16 dez. 2020.

MATTOS, S. Mídia controlada: a história da censura no Brasil e no mundo. São Paulo: Paulus, 2005.

MOTTER, P. O uso político das concessões das emissoras de rádio e televisão no governo Sarney. Comunicação \& Política, Rio de Janeiro, vol. 1, n. 1, p. 89-116, 1994.

OCDE. A Caminho da Era Digital no Brasil. OCDE, 2020a. Disponível em: <http://www.oecd. org/digital/a-caminho-da-era-digital-no-brasil-45a84b29-pt.htm>. Acesso em: 28 out. 2020.

. Avaliação da OCDE sobre Telecomunicações e Radiodifusão no Brasil 2020. OCDE, 2020b. Disponível em: <https://www.oecd.org/competition/avaliacao-da-ocde-sobre-telecomunicacoes-e-radiodifusao-no-brasil-2020-0a4936dd-pt.htm>. Acesso em: 28 out. 2020.

PERUZZO, C. Rádios Comunitárias no Brasil: da desobediência civil e particularidades às propostas aprovadas na CONFECOM. Encontro Anual da Compós, v. 19, 2010. Disponível em: <http://compos.com.puc-rio.br/media/g6_cicilia_peruzzo.pdf>. Acesso em: 21 jun. 2020. 
PIERANTI, O. P. Políticas Públicas de Radiodifusão no Governo Dilma. Brasília, DF: Universidade de Brasília, Faculdade de Comunicação, 2017.

A radiodifusão pública resiste: a busca por independência no Brasil e no Leste Europeu. Brasília, DF: Universidade de Brasília, Faculdade de Comunicação, 2018.

Memória das Comunicações no Brasil: entrevistas. Brasília, DF: Universidade de Brasília, Faculdade de Comunicação, 2019.

PRATA, J.; BEIRÃO, N.; TOMIOKA, T. Sérgio Motta: o Trator em Ação. São Paulo: Geração Editorial, 1999.

RAMOS, M. Uma nova legislação para as comunicações brasileiras e o paradoxo da radiodifusão. Tendências XXI, ano II, n. 2, set. 1997, p. 176-182.

TELETIME. Poder de outorga complica relatório da lei das agências. Teletime, 21 ago. 2007. Disponível em: <https://teletime.com.br/21/08/2007/poder-de-outorga-complica-relatorio-da-lei-das-agencias/?amp>. Acesso em: 30 out. 2020.

Artigo recebido em 31/10/2020 e aprovado em 31/01/2021. 